Research Article

\title{
Histopathological Changes in Tomato (Lycopersicum esculentum L.) Plants Induced by the Infection of Fusarium oxysporum f. sp. lycopersici, the Cause of Tomato Wilt Disease
}

\author{
Maryam Yousaf ${ }^{1}$, Salman Ahmad ${ }^{1 *}$, Romana Anjum² and Muhammad Zeeshan Majeed ${ }^{3}$
}

${ }^{1}$ Department of Plant Pathology, College of Agriculture, University of Sargodha, Sargodha, Pakistan; ${ }^{2}$ Department of Plant Pathology, University of Agriculture, Faisalabad, Pakistan; ${ }^{3}$ Department of Entomology, College of Agriculture, University of Sargodha, Sargodha, Pakistan.

\begin{abstract}
A study was conducted to evaluate the structural and functional modifications in tomato Lycopersicum esculentum nursery seedlings in response to tomato wilt disease caused by fungus Fusarium oxysporum f. sp. lycopersici (FOL). Two months old tomato seedlings were grown under normal conditions in green house and were artificially inoculated with FOL conidial suspension of $1 \times 10^{6}$ conidia $/ \mathrm{mL}$ by drenching method. Untreated plants served as control. First disease symptoms appeared after seven days of inoculation and seedlings became wilted within 30 days post inoculation. Stems from wilted as well as control seedlings were cross sectioned to observe the histopathological modifications. Wilted cross sections represented the cell wall disintegration and disruption of the tissues along with the blockage in xylem and phloem vessels due to the tylone production. Hyphal growth and proliferated hyphae inside the root cortex were also observed. We concluded that FOL fungus penetrated into the cell wall of the tomato seedlings through hyphae and proliferated into the cortex. Later on, it progressed into the roots and stem, started blocking of the xylem and phloem by producing tylones and deposition of phenolic compounds that supported the FOL to further multiply until the seedlings started wilting and became dead. Moreover, a gradual decrease in shoot height and root length was also observed in the diseased plant as compared to healthy plants.

Received | April 05, 2021; Accepted | June 21, 2021; Published | August 16, 2021

*Correspondence | Salman Ahmad, Department of Plant Pathology, College of Agriculture, University of Sargodha, Sargodha, Pakistan; Email: salman.ahmad@uos.edu.pk

Citation | Yousaf, M., S. Ahmad, R. Anjum and M.Z. Majeed. 2021. Histopathological changes in tomato (Lycopersicum esculentum L.) plants induced by the infection of Fusarium oxysporum f. sp. lycopersici, the cause of tomato wilt disease. Sarbad Journal of Agriculture, 37(4): 1128-1133. DOI | https://dx.doi.org/10.17582/journal.sja/2021/37.4.1128.1133

Keywords | Fusarium oxysporum f. sp. lycopersici, Histopathology, Hyphal proliferation, Tomato wilt, Tylone production
\end{abstract}

\section{Introduction}

$\mathrm{T}$ omato (L. esculentum L.) is most important and famous fruit vegetable worldwide. It belongs to the family Solanaceae and it was originated from Peru and Mexico (Verma et al., 2018). This fruit is full of nutrients, antioxidants, vitamins $\mathrm{A}$ and $\mathrm{C}$; hence, nutritionists recommended its use for managing cholesterol and weight loss ( $\mathrm{Mj}$ et al., 2017). Ripe tomato fruit consists of various vitamins, amino acid, glucose and fructose. It is a rich source of minerals which include $\mathrm{Mg}, \mathrm{Ca}, \mathrm{P}, \mathrm{Fe}, \mathrm{Na}, \mathrm{K}, \mathrm{Cu}$ and $\mathrm{S}$. It also contains protein, fiber and carbohydrates. Tomato has lycopene which is considered as an important component that helps to lower the chances of prostate cancer, heart diseases and age-related diseases (AVRDC, 2003). Tomato is cultivated all over Pakistan due to its high demand. Annually, 599.7 thousand tons of tomato is produced on the area of 63.2 thousand hectares in Pakistan (Akhtar et 
al., 2017). There are many limiting factors of tomato production like, early blight, verticillium wilt, bacterial canker, tomato spotted wilt, anthracnose, and bacterial wilt (Mardi et al., 2002). Now a days, tomato wilt disease (TWD) is the major limiting factor of tomato production in Pakistan. About 20-80\% disease losses has been reported worldwide (Worku and Sahela, 2018). In Pakistan, 49.5\% disease losses have been recorded due to this tomato wilt disease (Akhtar et al., 2017). Extreme losses of this disease have been reported under favorable conditions of wetness at fruit maturity stage (Akhtar et al., 2017).

As FOL is a soil borne fungus, it survives in soil in the form of dormant propagules known as chlamydospores. The germination of chlamydospores depends on the presence of host roots. At the time of penetration into the roots, the hyphae of the FOL adhere to the roots and attack the cortical cells of the root and are penetrated intracellularly through xylem pits into vascular system. Later on, the fungus uses an exclusive pathway for causing infection where it colonizes the entire xylem vessels. The fungus then expedites its colonization into the host and starts producing microconidia which are moved to upwards using sap stream. Subsequently, microconidia germinate and penetrate into upper vessels. Accumulation of hyphae into the plant vessels together with the combination of plant-pathogen interactions results in the release of gums, toxins, gels, and develop tyloses, which cause blockage of vessels resulting wilt symptoms (McGovern, 2015; Srinivas et al., 2019). Symptoms of tomato wilt disease clearly seen on leaves as vein clearing, yellowing, curling of margins, stunting, drying of leaves and stem, development of adventitious roots, marginal necrosis, defoliation, and at the end whole plant gets died (Agrios, 1988; Patil et al., 2011).

Electron and fluorescence microscopy have been used to study the tomato plant interaction and ultra-structures of FOL. The findings of electron microscopy have shown that microconidia are largely associated structures with xylem vessels. Further, it was found that microconidia germinate, and mycelia take about 10-14 days to enter into the cortex after inoculation. It was further found that hyphae in between the tissues of vessels were thicker with diameter of $1.5-2 \mu \mathrm{m}$. The physical structures within the vessels cannot stop the growth of microconidia within the vessels. FOL makes the vessels smooth, while the uncolonized vessels are granular (Srinivas et al., 2019). What further changes take place in tomato wilt infected tissues are still to be investigated.

The hypothesis of current study was that tomato wilted plants exhibit histopathological changes which need to be explored in FOL infected roots of tomato plants. Tomato roots and stem structural changes due to various abiotic factors have already been reported (Ortiz et al., 2014). This research work was planned to study the response of tomato plant to fungal infection under controlled environment to understand the mechanism of penetration, infection and colonization of the fungus.

\section{Materials and Methods}

\section{Collection of germplasm and pathogenicity trial}

A total of thirty plants of local tomato variety Roma were potted with three replications under normal soil and environmental conditions in green house of the Department of Plant Pathology, University of Agriculture Faisalabad. Infected samples were collected from the greenhouse on the basis of symptoms. Infected plant parts were cut from sample and washed in distilled sterilized water, after that sterilized parts were placed on potato dextrose agar and incubated at 282 for seven days. FOL isolates 01, 02, 03, 37, 61 and 67 whose pathogenicity was confirmed previously were used in this experiment. Ten potted tomato plants were subjected to artificial inoculation with $1 \times 10^{6}$ conidia/mL spore suspension of FOL (Ortiz et al., 2014). After 35 days of artificial inoculation, potted tomato plants showed partial to complete wilting symptoms such as yellowing of leaves, clearing of veins and drying of leaves and stems. Untreated five tomato plants served as control. Physiological parameters of healthy and inoculated plants were also compared to observe the effect of FOL infection.

\section{Histopathological studies}

For histopathological studies, $10 \mathrm{~mm}$ transverse slices of stems and roots of healthy and diseased tomato plants were preserved in Formalin acetic acid (acetic acid 5\%, v/v formalin 10\%, distilled water $35 \%$ and ethyl alcohol 50\%) for the 48 hours (Anjum et al., 2016). For long term storage, fixed samples were then transferred to Acetic ethanol solution (ethanol 75\% and v/v acetic acid 25\%). Fixed stems and roots were sectioned into $3 \mathrm{~mm}$ transvers portions by freehand 
sectioning. To prepare permanent slides, the sections were dehydrated through the serial dilutions of ethanol and stained using standard double-staining technique of safranine and fast green stains (Anjum et al., 2016). Real time images were taken with microscope camera after observing under OMAX microscope model G017075953. The experiment was set up in a completely randomized design. The data was subjected to analysis of variance (ANOVA) and means were computed by using software Statistics 8.1 .

\section{Results and Discussion}

\section{Morphological parameters}

For the morphological studies of the isolates, color of colony, mycelial development pattern, radial development and sporulation parameters were recorded after 7 days of incubation. The isolates showed white, pink, creamy white and purple to violet colours. The length of the macroconidia was between $11-17 \mu \times 2.5-4 \mu$, while the length of microconidia was $2.5-15 \mu \times 2-3 \mu$, and chlamydospores were around $7-12 \mu \times 3-5 \mu$. Macrconidia showed 3-5 septation while microconidia were aseptate (Figure 1). The isolates showed high diversity in the form of culture and morphology.
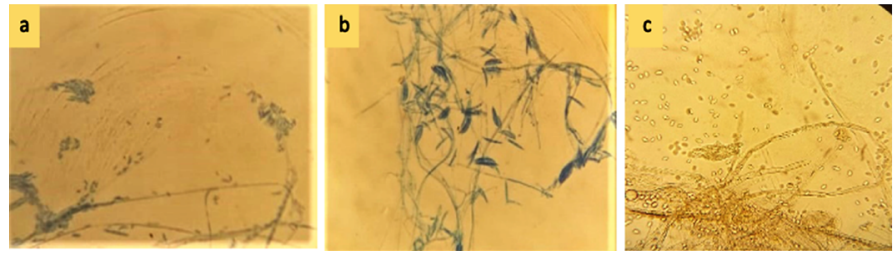

Figure 1: a) Microspores, b) Macrospores and c) Chlamydospores.

Comparison of shoot height and root length of healthy and diseased plants

Shoot height and root lengths of both healthy and diseased plants were taken to check the effect of FOL on physiological parameters. A gradual decrease in shoot height and root length was observed in diseased plants as compared to healthy (Figure 2). Cross sections of stem showed that epidermis created polygonal cells in between a thinner cuticle, while 1 or 2 coatings of collenchyma and 6-8 coatings of parenchyma were also observed in cortex (Figure 3). The primary vascular system was with the same style, although at the lateral stages, plant showed secondary growth. The xylem was found organized and had large vessels about $105-160 \mu \mathrm{m}$ in diameter. The xylem further showed profused radial and paratracheal parenchyma through lignified walls with obvious amyloplasts, tracheids and sporadic xylem fibers. The primary xylem showed non- lignified parenchyma and vessels with reduced diameter as compared to pith. The phloem was observed with larger sieve cells and smaller companion cells. The cross section of collar showed same histological pattern as observed in stem, where epidermis was replaced with periderm (cork, phellogen and phelloderm) and the parenchyma cells had several amyloplast. The vessels and parenchyma had large number of xylem fibers with visible secondary walls. The pith was thick and made of parenchyma cells. In secondary growth of roots, parenchymatic secondary cortex showed cell partition and wall lignification; although did not form the phelloderm. Roots had secondary xylem as was observed in collar region with no pith in the center. Different stains have different effects on cellular forms associated with other tissues (Figure 3).

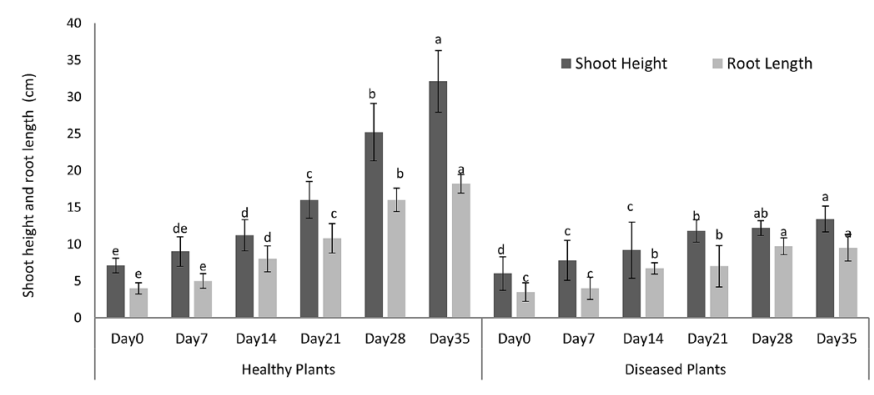

Figure 2: Comparison of shoot height and root length of healthy and diseased plants of tomato. Alphabets indicate statistical difference among treatments (factorial ANOVA; HSD test at $\alpha=0.05$ )
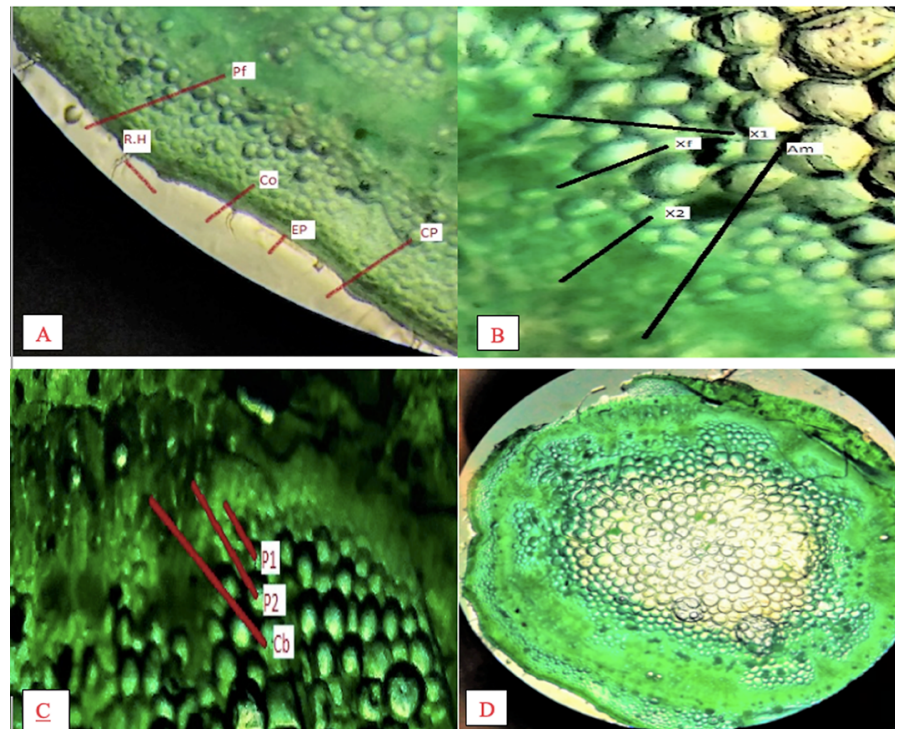

Figure 3: Staining of tomato plant parts; root and collar region with fast green and safranin. (A) presence of $R$.H, root hair; Co, collenchyma; Pf, periphloematic fibers; Ep, epidermis; $C$ p, cortical parenchyma;(B) $X 1$, primary xylem; $X 2$, secondary xylem; $X f$, xylem fibers; Am, amyloplasts;(C) P1, primary phloem; P2, secondary phloem; $C b$, cambium;(D) whole healthy root section. 
Anatomy of diseased plant tissues

FOL colonized xylem including collar, stem and root portions of the plant. Hyphae and microconidia of fungus occupied the xylem bundles. Lack of amyloplast in parenchyma and degradation of xylem fibers clearly represented the presence of FOL. Green colour staining indicated the presence of chitin and glucan while red colour staining indicated the presence of gel in cell wall (Figure 4). Cortex thickness and inner phloem zone thickness was higher while xylem zone thickness and number of xylem vessels were lower in diseased samples compared to healthy (Figure 5). Similarly, stem diameter, vascular cylinder thickness and vascular tissue thickness were higher while pith thickness was lower in diseased samples compared to healthy (Figure 6).

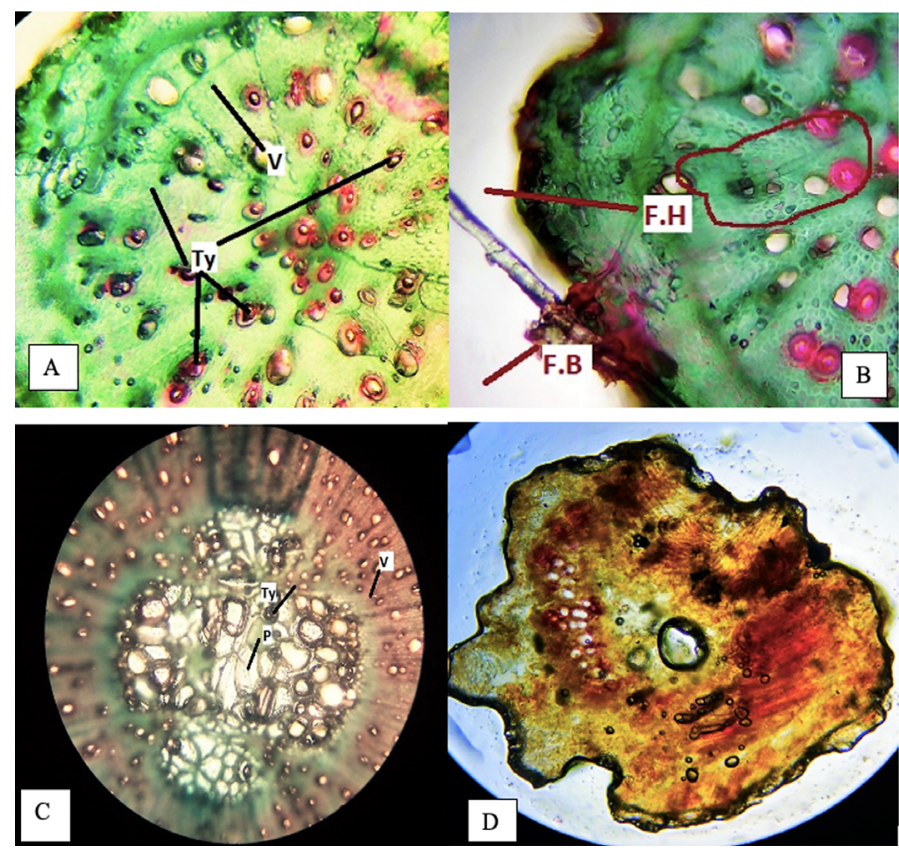

Figure 4: Diseased samples stained with fast green and safranin. (A) Ty; Tylosis formation starts and vascular bundles disperse. (B) fusarium hyphae emerge from the branch. $(C)$ dispersion of vascular bundles, tylosis occurring and disturbing the phloem. (D) full disintegrated cell portions and death of plant.

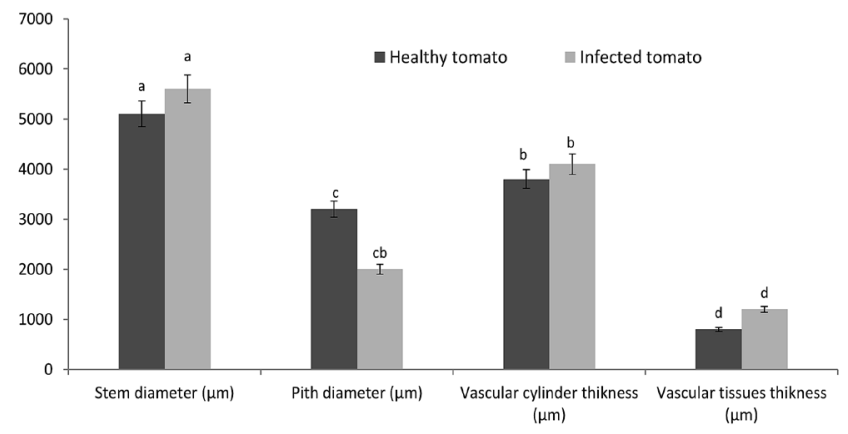

Figure 5: Comparison of plant parameters between healthy and diseased samples. Alphabets indicate statistical difference among treatments (factorial ANOVA; LSD test at $\alpha=0.05$ ).

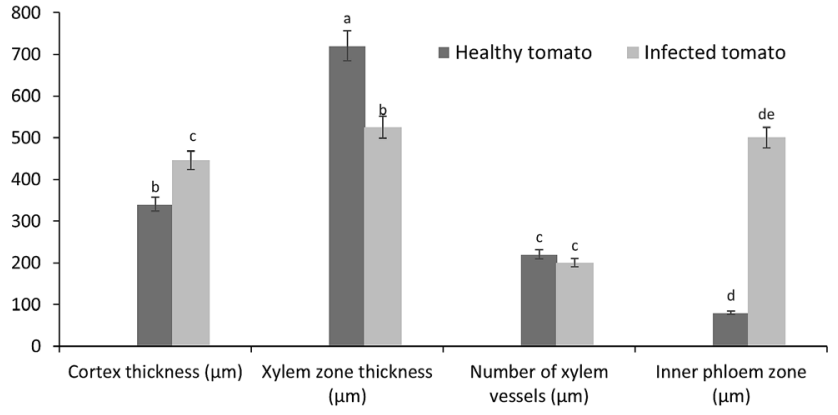

Figure 6: Comparison of plant parameters between healthy and diseased samples. Alphabets indicate statistical difference among treatments (factorial ANOVA; LSD test at $\alpha=0.05$ ).

FOL colonization was observed during this study in root, stem and collar region. This has confirmed the ability of FOL to penetrate through the root system and its colonization through vascular root system. This is in agreement with already available reports (Bishop and Cooper, 1983; Ortiz et al., 2014). FOL infections in collar have confirmed that colonization takes place from the path of periderm to pith through parenchyma tissues. Similar colonization has been reported in infections caused by $F$. solani f. sp. pisi, in which after penetration into the epidermis the fungus colonized parenchyma tissues in the cortex, and intercellular and intracellular growth of tissues took place as hyphae grew radially. Parenchyma are the tissues which facilitate the movement of the fungus in the tissues; however, there are also reports that they have also role in the defense mechanism of the plant (Stahl et al., 1994; Lian et al., 2020).

In our findings, microconidia and hyphae were found in tissues of vessels which means injuries are caused by these two structures. In response to injuries, it was observed that vessels produced tyloses structures. Moreover, primary xylem showed non-lignified parenchyma, and vessels were with reduced diameter as compared to pith. Further, the phloem was observed with larger sieve cells and smaller companion cells. In fact, all these were the defense mechanisms shown by the tomato plant tissues to defend themselves against the infection of FOL. This is in line with previous findings (Ortiz et al., 2014). We have also observed excessive changes in different structures of root and stem which include thickness of pith, secondary growth of roots, partition and wall lignification. All these changes in the tissues were in reaction to infection of FOL in cambium cells (Ouellette et al., 2006). Further, these changes may also be due to hyperplasia and hypertrophy that cause destruction of 
phloem, sieve cells and companion cells. Hypertrophy is also considered as defense mechanism of plants against diseases (Beckman and Roberts, 1995). During hypertrophy, growth promoting substances like ethylene are also produced (Ouellette et al., 2006).

We have also observed reduction in amyloplasts which are present in parenchyma cells. It has been reported that through this mechanism plant tissues deplete carbohydrates which are present in amyloplasts particularly when infection is caused by the pathogens. This finding is in accordance with the findings of Saniewska et al. (2004). It was also observed in our study that lignin degraded in the tissues. This is in line with the previous findings in which when F. oxysporum caused infection lignin degradation was observed (Niemann et al., 1991).

Finally, the stains we used in our study to differentiate healthy and diseased tissues remained very effective. The stains helped a lot to study the structures of pathogen and histopathological structures, and the cell organelles. Similar stains have been previously used and remained effective to study the diseased tissues (Ortiz et al., 2014).

\section{Conclusions and Recommendations}

Our findings concluded that FOL have caused significant changes in xylem fiber and caused clogging of vessels. We have further observed formation of tylosis and production of gel in the tissues which caused hypertrophy. It is concluded that all these changes cause disturbance in water uptake resulting in mineral shortage and plant died.

\section{Novelty Statement}

In this study, we conducted comparative study of histopathology to observe the changes which take place during infection of FOL in tomato plant tissues. The study revealed the mechanism of infection of FOL in tomato plants which has not been studied previously in Pakistan.

\section{Author's Contribution}

SA conceived the research idea, developed protocol and supervised the study. MY conducted experimentation and wrote initial draft. RA provided technical assistance during the study and technically proofread the manuscript. MZM performed the statistical analysis and prepared figures.

\section{Conflict of interest}

The authors have declared no conflict of interest.

\section{References}

Agrios, G.N. 1988. Studied the symptoms of Fusarium oxysporum. Plant Pathology, $3^{\text {rd }}$ Edition Academic press, Inc. New York. pp. 803.

Akhtar, T., Q. Shakeel, G. Sarwar, S. Muhammad, Y. Iftikhar, M.I. Ullah, M. Mubeen and A. Hannan. 2017. Evaluation of fungicides and biopesticides for the control of Fusarium wilt of tomato. Pak. J. Bot., 49(2): 769-774.

Anjum, R., S.T. Sahi and I.A. Khan. 2016. Histopathological changes in response to Ceratocystis manginecans in mango (Mangifera indica). Pak. J. Agric. Sci., 53(1): 195-199. https://doi.org/10.21162/PAKJAS/16.4861

AVRDC. 2003. Asian vegetable research and development corporation, progress report. In vivo evaluation of eggplant and tomato lines for bacterial wilt resistance. In: AVRDC Progress Report 2002. AVRDC publication number 03-563 Tainan: AVRDC-The World Vegetable Center.

Beckman, C.H. and E. Roberts.1995. On the nature and genetic basis for resistance and tolerance to fungal wilt diseases of plants. J. Adv. Bot. Res., 21(3): 36-77. https://doi.org/10.1016/S00652296(08)60008-7

Bishop, C. and R.M. Cooper. 1983. An ultrastructural study of vascular colonization in three vascular wilt diseases I. Colonization of susceptible cultivars. Physiol. Plant Pathol., 23(3): 323-343. https://doi.org/10.1016/00484059(83)90018-8

Lian, C., R. Liu, J. Luo, F. Yang, S. Zhang and B. Fei. 2020. The morphological characteristics and classification of vascular parenchyma cells in bamboo, Phyllostachys edulis (Carr.) J. Houz. Holzforschung., 74(9): 829-838. https://doi. org/10.1515/hf-2019-0241

Mardi, D., B. Janet and W. Paul. 2002. Organic Greenhouse Tomato Production. Fayetteville. AR 7270.

McGovern, R.J. 2015. Management of tomato diseases caused by Fusarium oxysporum. J. 
Crop Protect., 73(2): 78-92. https://doi. org/10.1016/j.cropro.2015.02.021

Mj, B., K. Bisen, C. Keswani and H. Singh. 2017. Biological management of Fusarium wilt of tomato using biofortified vermicompost. J. Micosphere., 8(3): 467-483. https://doi. org $/ 10.5943 /$ mycosphere/8/3/8

Niemann, G.J., J.J. Boon, J.B. Pureveen, G.B. Eijkel and E.van der Heijden.1991. A microanalytical approach to plant tissue characterization: A comparativestudyofhealthyandfungus-infected carnation by pyrolysis-mass spectrometry. J. Anal. Appl. Pyrol., 19(2): 213-236. https://doi. org/10.1016/0165-2370(91)80045-A

Ortiz, E., M. Cruz, L. M. Melgarejo, X. Marquínez and L. Hoyos-Carvajal.2014. Histopathological features of infections caused by Fusarium oxysporum and $F$. solani in purple passion fruit plants (Passiflora edulis Sims). J. Phytopathol., 40(2): 134-140. https://doi.org/10.1590/0100$5405 / 1910$

Ouellette, G.B., C.Mohamed, and M.Simard.2006. Histopathology of Fusarium wilt of staghorn sumac (Rhus typhina) caused by Fusarium oxysporum f. sp. callistephi race 3. III. Host cell and tissue reactions. J. Phytoprotect., 87(1): 1727. https://doi.org/10.7202/013967ar

Patil, S., S. Sriram and M. Savitha. 2011. Evaluation of nonpathogenic Fusarium for antagonistic activity against Fusarium wilt of tomato. J. Biol. Contr., 25(2): 118-123.

Saniewska, A., B. Dyki and A. Jarecka. 2004.
Morphological and histological changes in tulip bulbs during infection by Fusarium oxysporum $\mathrm{f}$. sp. tulipae. Phytopathol. J. Polonica., 34(1): 2139.

Srinivas, C., D.N. Devi, K.N. Murthy, C.D.Mohan, T.R. Lakshmeesha, B. Singh, N.K. Kalagatur, S.R. Niranjana, A. Hashem, A.A. Alqarawi, B. Tabassum, E.F. AbdAllah, S.C. Nayaka and R.K. Srivastava. 2019. Fusarium oxysporum f. sp. lycopersici causal agent of vascular wilt disease of tomato: Biology to diversity-A review. Saudi J. Biol. Sci., 26(7): 1315-1324. https://doi. org/10.1016/j.sjbs.2019.06.002

Stahl, D.J., A. Theuerkauf, R. Heitefuss and W. Schäfer. 1994. Cutinase of Nectria haematococca (Fusarium solani f.sp. pisi) is not required for fungal virulence or organ specificity on pea. J. Mol. Plant- Microb.e Interact., 7(6): 713725. https://doi.org/10.1094/MPMI-7-0713

Verma, N.P., Y.K. Kuldeep and B.K. Sinha. 2018. Efficacy of indigenous Trichoderma strain biocontrol against of Fusarium sp. tomato plant causal agent of (Solanum lycopersicon L.) in vitro Condition. Int. J. Curr. Microbiol. Appl. Sci., 7(3): 1578-1584. https://doi.org/10.20546/ ijcmas.2018.703.189

Worku, M. and S. Sahela. 2018. Review on disease management practice of tomato wilt caused Fusarium oxysporum in case of Ethiopia. J. Plant Pathol. Microbiol., 9(11): 2-4. https://doi. org/10.4172/2157-7471.1000460 